\title{
WATER INFORMATION SYSTEM PLATFORMS ADDRESSING CRITICAL SOCIETAL NEEDS IN THE MENA REGION
}

\author{
Shahid Habib ${ }^{\mathrm{a}}$, Claire Kfouri ${ }^{\mathrm{b}}$, Mark Peters ${ }^{\mathrm{c}}$ \\ ${ }^{a}$ NASA Goddard Space Flight Center, Greenbelt, Maryland, USA \\ ${ }^{\mathrm{b}}$ The World Bank, $1818 \mathrm{H}$ Street NW, Washington, DC, USA \\ ${ }^{\text {} U S ~ A g e n c y ~ f o r ~ I n t e r n a t i o n a l ~ D e v e l o p m e n t, ~ O f f i c e ~ o f ~ M i d d l e ~ E a s t ~ P r o g r a m s, ~ C a i r o, ~ E g y p t ~}$
}

Abstract: The MENA region includes 18 countries, the occupied Palestinian territories and Western Sahara. However, the region of interest for this study has a strategic interest in countries adjacent to the Mediterranean Sea, which includes, Morocco, Tunisia, Egypt, Lebanon and Jordan. The $90 \%$ of the water in the MENA region ${ }^{1}$ is used for the agriculture use. By the end of this century ${ }^{2}$, this region is projected to experience an increase of $3^{\circ} \mathrm{C}$ to $5^{\circ} \mathrm{C}$ in mean temperatures and a $20 \%$ decline in precipitation (IPCC, 2007). Due to lower precipitation, water run-off is projected to drop by $20 \%$ to $30 \%$ in most of MENA by $2050^{3}$. Reduced stream flow and groundwater recharge might lead to a reduction in water supply of $10 \%$ or greater by 2050 . Therefore, per IPCC projections in temperature rise and precipitation decline in the region, the scarcity of water ${ }^{4}$ will become more acute with population growth, and rising demand of food in the region. Additionally, the transboundary water issues will continue to plague the region in terms of sharing data for better management of water resources. Such pressing issues have brought The World Bank, USAID and NASA to jointly collaborated for establishing integrated, modern, up to date NASA developed capabilities for countries in the MENA region for addressing water resource issues and adapting to climate change impacts for improved decision making and societal benefit. This initiative was launched in October 2011 and is schedule to be completed by the end of 2015 .

\section{MENA TECHNICAL REQUIREMENTS}

Most of the MENA countries share a common set of requirements with some exceptions in the areas of locust monitoring, ground water assessment and monitoring and

Table I MENA Thematic Requirements

\begin{tabular}{|c|c|c|c|c|c|}
\hline Functional Requlrement & Egypt & Jordan & Tunisia & Lebsnon & Morocco \\
\hline Evapoltransplation & $x$ & $x$ & $x$ & $x$ & $x$ \\
\hline $\begin{array}{l}\text { Floods Delecton and } \\
\text { Mod?iling }\end{array}$ & $x$ & & $x$ & $\bar{x}$ & $\bar{x}$ \\
\hline Drought & $x$ & $\mathrm{x}$ & $x$ & $x$ & $x$ \\
\hline Climale Charge & $x$ & $x$ & & * & $x$ \\
\hline Ground Water Recharge & & $x$ & $x$ & & \\
\hline $\begin{array}{l}\text { Crop Mapping and } \\
\text { Irrigaton }\end{array}$ & $x$ & $\mathrm{x}$ & & * & $x$ \\
\hline Hydrological Modeling & $x$ & & & & $x$ \\
\hline Locus| Monitoring & & & $x$ & & $\mathrm{x}$ \\
\hline Fires & & & & $x$ & \\
\hline
\end{tabular}

cloud cover. The problem is further exacerbated if we do not get a good set of ground observations to validate and calibrate the models for their long term use. Our approach has been to learn and synthesize each MENA country requirements and understand the cliental base that will use the products for decision making. Table 1 provides a set of thematic requirements under this project.

\section{IMPLEMENTATION STRATEGY}

The main focus of this project is to address the most pressing societal issues which can be modeled and solved by utilizing NASA Earth Science remote sensing data products and hydrological models. Our approach will be to use NASA's Earth Observations research data products and models to study the entire MENA region. This will provide a global data sets for the region however with coarser resolutions and general boundary conditions. The next step, which involves regional remote sensing organizations and water related ministries to customize the models for country specific needs. This will further require validation and calibration of such models for their sustainable use. We are taking methodic steps in implementing their respective needs because: (a) each country's ability or technical capacity varies in order to receive and use such complex models (b) each country's openness in sharing in situ data and finally their ingenuousness efforts in engaging the real user communities. At the same time, a rapid transition to advance tools and techniques may be overwhelming and result in a less effective solution. Hence, we have evaluated best fit solutions by engaging each country's technical and operational experts from the onset. We therefore carefully segregate the problem into two discrete categories i.e., 'low hanging fruits' or phase 1 candidates and 'high hanging fruits' or phase II candidates. Phase I tasks will have a shorter period to realize whereas phase II activities will require longer time due multiple complexity issues.

\section{UTILIZATION OF DATA AND TOOLS}

The most common denominator in this project is utilizing NASA Earth Science research results to model and analyze the water resource issues for the MENA region. This important aspect falls under the applied research domain and satisfies how NASA, by engaging the user community, performs end to end science. Majority of NASA data and tools are open source and are readily available via the Internet. However, it requires expertise in remote sensing, 
modeling, atmospheric physics, engineering and computer science to access, interpret and customize data sets and models for one's parochial use. This can be a daunting task and this is where NASA assists the end user partners to enable this transition. As minimum, the following sensors, data sources and tools are used for the MENA project: Satellite Data: Near Real Time precipitation data from TRMM, land cover data products (e.g., land surface temperature, Normalized Difference Vegetation IndexNDVI) from Terra and Aqua MODIS instruments, soil moisture from AMSR, higher resolution data from Landsat and EO-1, GRACE, digital elevation model from SRTM and ASTER are primarily sensors used under this study. Table 3 provides a typical list of satellite products and resolution.

Table 3 NASA Earth Observation satellites and resolution

\begin{tabular}{|c|c|c|}
\hline Observation & Satellite Sensors & $\frac{\text { Resolution }}{5 \mathrm{~km} / 25 \mathrm{~km}}$ \\
Precipitation & TRMM, IR, Microwave/GPM & $300 \mathrm{~km}$ \\
Terrestrial Water Storage & GRACE/GRACE II & $25 \mathrm{~km}$ \\
Soil Moisture & AMSR-E/SMAP & $250 \mathrm{~m}$ \\
Land Cover Type & MODIS/VIIRS & $250 \mathrm{~m}$ \\
Irrigation Intensity & MODIS/VIIRS & $1 \mathrm{~km}$ \\
Leaf Area Index & MODIS/VIIRS & $1 \mathrm{~km}$ \\
Vegetation Fraction & MODIS/VIIRS & $30 \mathrm{~m}^{*}$ \\
Topography & SRTM & \\
\hline
\end{tabular}

The future sensors GPM, SMAP to be launched in 20132014 will provide higher resolution precipitation and soil moisture observations. This will further constrained the models to produce better results.

LANCE: Land Atmosphere Near Real Time Capability for Earth Observing Systems - NASA has set up a new system that provides a faster access to satellite data products in less then three hours from observations. This includes data from multiple atmospheric and land imaging sensors such as MODIS, OMI, AIRS and MLS. The system supports application users who are interested in monitoring and analyzing a wide variety of natural and anthropogenic activities. These are global data sets and downloads can be specific to region of interest (http://earthdata.nasa.gov/data/near-real-time-data). GEONETCast: This is a satellite based low cost data and product distribution network makes use of international geostationary meteorological satellites to provide global coverage. The receiver is DVB-S/S2 standard receiver capable of receiving $\mathrm{C}$ and $\mathrm{Ku}$ band signals. For the MENA region, EUMETSAT MSG satellite has the observable coverage. This system is capable of providing both archived and near real time vegetation cover, ocean color and meteorological data for the area under observation. The data source is from MSG, SPOT, AVHRR and MODIS. http://wv:w.eumetsat.int//Home/Main/DataAccess/EUMETCast/index.htm Evapotranspiration: Atmospheric-Land Exchange Inverse $\left(\right.$ ALEXI) ${ }^{5}$ and disaggregated ALEXI model (Figure 1) developed by Anderson et.al., is a powerful model that makes use of remotely sensed thermal infrared (TIR) and land surface temperature information for estimating evapotranspiration and detecting the onset and severity of drought. The model estimates ET by partitioning the energy

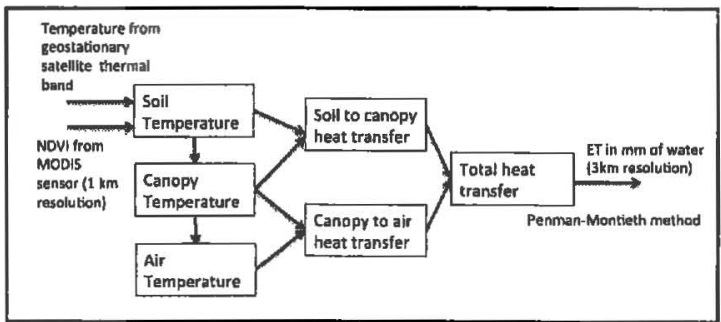

Figure I. ALEXI Model flow diagram

Table 2 Satel lite data and resolution used in ET calculations

\begin{tabular}{|l|l|l|l|l|}
\hline Scaie & $\begin{array}{l}\text { Spatial } \\
\text { resolution }\end{array}$ & $\begin{array}{l}\text { Temporal } \\
\text { resolution }\end{array}$ & $\begin{array}{l}\text { Current } \\
\text { Sensor }\end{array}$ & $\begin{array}{l}\text { Future } \\
\text { Sensor }\end{array}$ \\
\hline Coarse & $5-20 \mathrm{~km}$ & $15 \mathrm{~min}$ & $\begin{array}{l}\text { GOES } \\
\text { MSG } \\
\text { AIRS }\end{array}$ & $\begin{array}{l}\text { GOES } \\
\text { MSG } \\
\text { CrIS }\end{array}$ \\
\hline Moderate & $1 \mathrm{~km}$ & Daily & $\begin{array}{l}\text { MODIS } \\
\text { AVHRR } \\
\text { ATSR }\end{array}$ & $\begin{array}{l}\text { AVHRS } \\
\text { AVHR }\end{array}$ \\
\hline Fine & $60-120 \mathrm{~m}$ & $\begin{array}{l}\text { Once every } \\
\text { 5-16 days }\end{array}$ & $\begin{array}{l}\text { Landsat } \\
\text { ASTER }\end{array}$ & $\begin{array}{l}\text { LDCM } \\
\text { HyspIRI }\end{array}$ \\
\hline
\end{tabular}

available at the land surface. This is extracted by a difference of Net Radiation minus soi! heat conductance minus the sensible heat flux at the surface and top of atmosphere. The resultant value is calculated in $\mathrm{mm} / \mathrm{sec}$ using Penman-Monteith ET method. Similarly DisALEXI is constraint to operate on spatial resolution of $5-120 \mathrm{~m}$, where atmospheric forcing by land-surface behavior becomes more effective. For smaller size agriculture fields, commercial sensor may play a role in providing high resolution data. Table 2 provides a range of spatial resolutions of sensors used by ALEXI and DisALEXI.

Crop Mapping and Irrigation: ${ }^{6}$ This methodology presents a novel technique to map irrigated agriculture globally at $500 \mathrm{~m}$ spatial resolution with a combination of data from the MODIS (NDVI, NWDI) instrument and ancillary data on climate and agriculture. Irrigated crops are defined as that receives full or partial application of water to offset rainfall deficit under dry conditions. The method (Figure 2) uses image classification approach to the irrigation mapping problem, guided by climate based (Climate Moisture Index - CMI) index that identifies locations that require irrigation. The sub pixel estimation is also developed to identify the portion of individual pixel occupied by irrigated fields. This is to improve the accuracy of the results. A classification

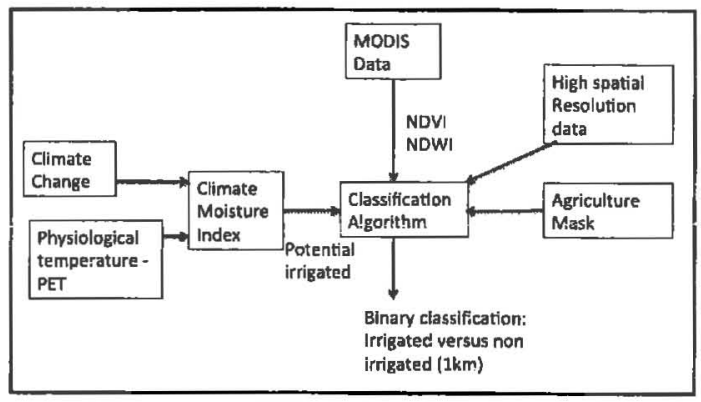

Figure 2. Crop mapping and irrigation flow diagram. 
algorithm based on machine technique is deployed to come up with a binary decision showing irrigated versus nonirrigated field. The high resolution imagery from Landsat or commercial sensors can be used to enhance the results. Flood Mapping and Modeling: ${ }^{7}$ The NASA Goddard Space Flight Center has near real time automatic global flood mapping model that utilizes MODIS data acquired through LANCE within few hours of acquisition. The flood maps indicate the flooded areas globally at $250 \mathrm{~m}$ resolution. The mapping algorithm enhancement is underway to make provision to include radar data to alleviate clouds and cloud shadow issues. The basic algorithm was developed at the uses (visible to near shortwave infrared range) a ratio of MODIS band 1 and band 2, and a threshold on band 7 to provisionally identify pixels as water. The floodwater is detected by overlaying the normal water mask. The flood modeling is based on Coupled Routing and Excess Storage model (CREST) ${ }^{10}$ hydrological model jointly developed by Oklahoma University and NASA. It provides a cell to cell simulation of subsurface and surface rainfall, water storage, runoff, and evapotranspiration. CREST is designed to simulate the spatiotemporal variation of water and energy fluxes and storages on a regular grid with the grid cell resolution being user-defined, thereby enabling global- and regional-scale applications. The scalability of CREST simulations is accomplished through sub-grid scale representation of soil moisture storage capacity (using a variable infiltration curve) and runoff generation processes. Climate Analysis: We will generate high-resolution climate change projections utilizing dynamical or statistical downscaling methods. The results will be analyzed to develop future impact or scenarios on precipitation, agriculture and natural disasters. This will help in providing uncertainty estimates and a physically based understanding of projected impacts. The $4^{\text {th }}$ Assessment Report of the Intergovernmental Panel on Climate Change (IPCC AR4) has indicated that climate change over the next century will affect rainfall patterns, river flows and sea levels all over the world. Climate change impacts are more pronounced when

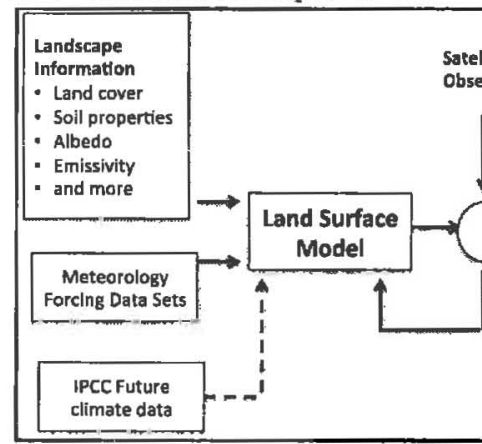
Satellite bservations

Figure 3. Land Data Assimilation System modeling framework. projections. Dartmouth Flood Observatory ${ }^{8,9}$. The detection technique

decreased mean precipitation, increased potential evapotranspiration, enhanced variability, and more frequent extreme events threatens both surface and ground water resources in the region. At the same time, climate change projections are limited by the coarse spatial resolution of global climate models and by scientific uncertainty regarding the rate and severity of predicted change. This presents the MENA region with a complex adaptation challenge that requires improved information systems, analysis tools, and platforms for coordinated response within and across countries.

NASA will assemble a database of historical meteorological records to be used in calibrating statistical algorithms. Where meteorological records are unavailable, highresolution reanalyses data will be used to fill gaps. NASA developed downscaling code for MENA. This code will be based on established empirical-statistical downscaling (ESD) methodologies, complemented with regionally adapted physiographic downscaling techniques. It is anticipated that downscaled scenarios can be produced at a nominal resolution as high as 90 meters for hourly fields, though confidence will be higher at moderate resolution (10$25 \mathrm{~km}$ ). Downscaled fields will be evaluated against historical records and dynamically downscaled future

Land Data Assimilation System (LDAS): " Our long term implementation goal is to provide an integrated comprehensive hydrological modeling framework that will make use of available observed data from multiple NASA satellites $^{12}$ during the computational process. Specifically this falls under the phase II of the project development cycle and is designated as 'high hanging fruits.' LDAS is a suite of hydrological and Land Surface Models where selected output state variables such as soil moisture, evapotranspiration and others are compared and corrected they also occur with other water stresses such as from increases in population and inadequate access to water and sanitation. For many parts of the MENA region there is an expected precipitation decrease over the next century of over $20 \%$, and warmer temperatures are simultaneously expected to increase the extreme events of droughts and floods. The combination of with the available satellite measurements. The output products of such simulations are further utilized in conducting agriculture planning, drought risk and ground water assessment studies. The region-specific LDAS, in addition to NASA Earth satellite data, is envisioned to use local surface observations, and publicly-avaiiable meteorological analyses to drive a suite of advanced land surface models, with the goal of providing regional scale gridded data of hydrological variables relevant to water resource planning and management. Furthermore, it will also have water routing and agriculture irrigation modules for flooding and crop 
mapping studies. The LDAS outputs will be compared with independent models, as discussed above, for comparative studies to improve the accuracy of the products. This integrated concept is further elaborated in Figure 3.

\section{VALIDATION AND CALIBRATION}

The core of the NASA MENA initiative is the development and implementation of a central water information system that will integrate hydrological data and analysis for operational use. The tools, described above, will require extensive interaction from the user community to acquire the field, and regional data sets to validate the models. Additionally, significant efforts will be required to adapt these models for each respective country. This will be accomplished by utilizing the actual regional data to calibrate the models. This will further optimize the models for their sustained usage; and eventually serve the users ${ }^{13}$ with accurate information for improved decision making.

\section{TRAINING AND CAPACITY BUILDING}

The most critical part of this undertaking is to provide the adequate level of training to ach MENA country's technical staff so they will eventually be improving the decision making process related to the water management issues. There will be seminars, hands on and on site training conducted during the course of this project. NASA will provide the initial training to each country experts initially. It will be responsibility of each country to further expand the knowledge to build additional capacity.

\section{SUMMARY}

The main focus of this mission is to engage the user community to ensure they are the prime benefactors of the products produced by using advanced tools and satellite data sets. The models will be transferred to the MENA countries for their long term use. It will be their responsibility to absorb all this knowledge and share with other relevant organizations within their own nation. It is anticipated, the transboundary issues pertaining to hydrological data will continue to present problems due to the sensitive nature of the data.

\section{ACKNOWLEDGEMENT}

The authors acknowledge the sincere efforts of additional team members in support of this project: Matt Rodell, Fritz Policelli, John Bolten, David Toll, Sujay Kumar and Ted Engman from NASA Goddard Space Flight Center; Martha Anderson from United States Department of Agriculture; Ben Zaitchik from Johns Hopkins University; John Mecikalski from University of Alabama and Mutlu Ozdogan from University of Wisconsin.

\section{REFERENCES}

1. MENA Water Overview: Transboundary Cooperation, IWRM Opportunities for Swedish Engagement, Paper 12, June 2007 2. Elasha, B.O., Mapping Climate Change Threats and Human Development Impacts in the Arab Region, Arab Human Development Report, UNDP 2010

3. Milly et al. 2005. "Global pattern of trends in streamflow and water availability in a changing climate", Nature, Vol 438/17, November 2005.

4. Habib, S., "The hydrologic cycle and the sustainability of water resources," Elements of Life, World Meteorological Organization, ISBN 92-63-11021-2, 2007, 62-65.

5. Anderson, M.C., W. P. Kustas, J. M. Norman, C. R. Hain, J. R. Mecikalski, L. Schultz, M. P. Gonz alez Dugo, C. Cammalleri, G. d'Urso, A. Pimstein, and F. Gao, "Mapping daily evapotranspiration at field to global scales using geostationary and polar orbiting satellite imagery, " Hydrology. Earth System Sciences Discussions, 1-34, July 2010.

6. Ozdogan, M and Gutman, G.; "A new methodology to map irrigated areas using multi-temporal MODIS and ancillary data: An application example in the continental US, "Remote Sensing of Environment 112, 3520-3537, 2008

7. Habib, S., Policelli, F., Irwin, D., Korme, T., Adler, B., and Hond, $Y$., "Application of satellite observations to manage natural disasters in Lake Victoria basin," IGARSS 2009

8. Brakenridge, G.R., et. al., Active Archive of Large Floods, 1985-present, Dartmouth Flood Observatory, http://www.dartmouth.edu/\%7Efloods/Archives/index.html 9. Brakenridge, G. R., Satellite gaging reaches: A strategy fo MODIS-based river monitoring, International Symposium of Remote Sensing, Crete, Greece, 22-27, Sep 2002

10. Wang, J., Yang, H., Gourley, J., Khan, S., Yilmaz, K., Adler, R., Policelli, Fr., Habib, S.,Irwin, D., Limaye, A., Korme, T., and Pkello, L., "The couple routing and excess storage (CREST) distributed hydrological model "' Hydrological Science Journal (56(l), 84-98, 2011

11. Rodell, M., P. R. Houser, U. Jambor, J. Gottschalck, K. Mitchell, C. J. Meng, K. Arsenault, BCosgrove, J. Radakovich, M. Bosilovich, J. K. Entin, J. P. Walker, D. Lohmann, and D. Toll, March 2004: The global land data assimilation system BAMS, $381-394$.

12. Zaitchik, B. F., M. Rodell, and R. H. Reichle, 2008:

Assimilation of GRACE terrestrial water storage data into a Land Surface Model: Results for the Mississippi River basin. Journal of Hydrometeorology, 9, 535-548.

13. Habib, S., "Utilizing Earth Science Observations for Applied Research", Asian Journal of Geoinformatics, Volume 9, No. 1, ISSN 1513-6728, March 2009. 